ăn ít muối. Trong khi tỷ lệ bệnh đái tháo đường đang gia tăng ở nhiều nước đang phát triển trong thời gian gần đây, một phần là do sự ưa thích ngày càng tăng đối với chế độ ăn uống bao gồm carbohydrate béo và tinh chế và béo phì. Vì vậy, việc điêu trị cùng với kiểm soát chặt chẽ đường huyết thì vấn đề truyền thông và tư vấn cho người bệnh cũng là một nhân tố vô cùng quan trọng trong việc điều trị tích cực nhằm ngăn ngừa biến chứng của bệnh nhằm nâng cao chất lượng cuộc sống và kéo dài của người bệnh ĐTÐ [5]. Do đó, công tác truyền thông giáo dục sức khỏe phòng ĐQN rất quan trọng đối người bệnh. Nhân viên y tế cần chú trọng tư vấn cho người bệnh để họ thực hiện tuân thủ thực hành dự phòng đột quỵ não.

\section{KẾT LUÂ̂N}

- Người cao tuổi mắc bệnh đái tháo đường type II có trình độ văn hóa chưa cao.

- Người cao tuổi mắc bệnh đái tháo đường type II chưa tuân thủ thực hành về dự phòng các nguy cơ gây đột quy còn chiếm tỷ lệ cao.

TÀI LIẸU THAM KHẢO
1. Bùi Thị Châm (2013), Kiến thức, thực hành phòng biến chứng và các yếu tố liên quan của bệnh nhân đái tháo đường type 2 tại Bệnh viện Đa khoa Bắc Giảng năm 2013. Luận văn thạc sỹ, trường đại học y tể công cộng.

2. Nguyến Văn Chi (2016). Cập nhật chẩn đoán và xứ trí đột qui não cấp. Hội nghị tim mạch toàn quốc 2016. Hối tim mạch Quốc Gia Viêt Nam.

3. Nguyển Thi Hồng Đan (2010). Kiến thức, thực hành phòng biến chứng của người bênh ĐTĐ type 2 tại huyện Khoải Châu, tỉnh Hưng Yền năm 2010. Luận văn thac sỹ, trường đại học y tế công cộng

4. Phạm Manh Hùng (2019). Các yếu tố nguy cơ thường gặp của bệnh tim mạch. Hội tim mạch học quốc gia Viêt Nam, tr.11

5. Hà Thị Huyền (2016). Kiến thức, thái độ, hành vi và nhu cầu chăm sóc y tế của bênh nhân đái tháo đường týp 2 đang điều trị tại phòng khám nội tổng hợp bệnh viện đa khoa tỉnh Kon Tum tháng 7 năm 2016. Sở y tế Kom Tum.

6. Đố Duy Phương (2015). Kiến thức, thực hành phòng biến chứng và môtt số yếu tố liến quan của người bệnh ĐTĐ tuyp 2 tại Bệnh viện Đa khoa khu vực Hồng Ngự tỉnh Đồng Tháp nẳm 2015. Luận vằn thạc sỹ, trường Đại học y tế công cộng.

7. Nguyến Thi Thắm (2017). Thực trang kiến thức và thức hành phòng biến chứng cuả người bệnh ĐTĐ type 2 điêu trị ngoại trú tại bệnh viện đa khoa thành phố Hà Tĩnh. Luận văn thạc sĩ, trường Đại học Điều dưỡng Nam Định

\title{
CHẨN ĐOÁN VÀ KẾT QUẢ PHẪU THUÂT TỔN THƯƠNG ĐộNG MACH DO GÃY TRÊN LỒI CẦU XƯO'NG CÁNH TAY Ở TRẺ EM TÁ BỆNH VIỆN HỮU NGHI VIỆT ĐỨC
}

\author{
Đoàn Quốc Hưng ${ }^{1,2}$, Nguyễn Văn Đàn ${ }^{1}$, Vũ Ngọc Tú ${ }^{1,3}$
}

\section{TÓM TẮT}

Mục tiêu: Mô tả đặc điểm chẩn đoán, hình thái giải phẫu bệnh, phương pháp phẫu thuật và kết quả sớm sau mổ ở bệnh nhân gãy trên lồi cầu xương cánh tay tổn thương mạch máu. Phương pháp: Nghiên cứu mô tả cắt ngang tất cả bệnh nhi chẩn đoángãy trên lồi cầu xương cánh tay kèm tổn thương mạch máu, đã phẫu thuật tại Bệnh viện Việt Đức từ 01/01/2015 đến 31/12/2020. Kết quả: 56 BN đủ tiêu chuẩn nghiên cứu, tuôi trung bình là $6.3 \pm 2.7$, tî lệ nam/nữ 2/1. Đa số trường hợp cónguyên nhân là do tai nận ngã chống tay $(87.5 \%)$. Phần lớn bệnh nhân vần có bàn tay hồng $(96.4 \%)$, ấm $(76.8 \%)$ nhưng mạch quay mất hoặc yếu. Siêu âm trước mổ

\footnotetext{
${ }^{1}$ Trường Đại học Y Hà Nội

${ }^{2}$ Bệnh viện Việt Đức

${ }^{3}$ Bệnh viện Đại học Y Hà Nội

Chịu trách nhiệm chính: Đoàn Quốc Hưng

Email: hung.doanquoc@gmail.com

Ngày nhận bài: 1/4/2021

Ngày phản biên khoa học: 25/4/2021

Ngày duyệt bài: 19/5/2021
}

$100 \%$ trường hợp nhưng chỉ phát hiên có tổn thương ĐM ở 7 BN (17.6\%); cắt lớp vi tính thực hiện ở 37 BN phát hiện tôn thương động mạch cánh tay trên 36 BN (97.3\%). Tổn thương giải phẫu bênh trong mổ chủ yếu là co thắt mạch (38 $\mathrm{BN}-53.6 \%$, nong mạch bằng sonde Fogarty và phong bế áo ngoài), đụng giâp ĐM 16 BN-28.5\% (cắt nối trực tiếp hoặc ghép mach), huyết khối ĐM 2 BN (mở Đ̇M lây $\mathrm{HK}$ ). Sau mổ, tất cả bệnh nhân đều có bàn tay hồng ấm, mạch quay bắt rõ trở lại ở $87.5 \%$ bệnh nhân. Kết luận: Gãy trên lồi cầu xương cánh tay là một gãy xương thường gặp ở trẻ em, với tỉ lê tổn thương mach khá cao. Cần phối hợp siêu âm và chụp cắt lớp để xác định tổn thương. Phẫu thuât vừa là biên pháp điều trị lưu thông mach, vừa là biện pháp chẩn đoán xác định tổn thương thực sự động mach.

Tư khóa: Gãy trên lồi cầu xương cánh tay, trẻ em, chấn thương động mạch cánh tay.

\section{SUMMARY \\ DIAGNONIS AND RESULT OF SURGERY OF SUPRACONDYLAR FRACTURE WITH BRACHIAL ARTERY INJURY IN CHILDREN AT VIET DUC HOSPITAL}


Objectives: Describe characteristic diagnosis, pathological morphology, surgery method and early outcome after surgery of supracondylar fracture with brachial artery injury. Methods: Descriptive crosssectional study describes all patients that was diagnosed supracondylar fracture with brachial artery injury and was operated at Viet Duc Hospital from 01/01/2015 to 31/12/2020. Result:A total of $\mathbf{5 6}$ patients were included. Average age was $6.3 \pm$ 2.7, ratio male/ female $\sim 2 / 1$ and there was no difference between right and left hand. Activities accident was about $87.5 \%$ of causes.Most patients had pink (96.4\%) and warm $(76.8 \%)$ hand, but pulselessness. Ultrasound was done for all patients, but the brachial artery lession was founded only in 7 cases $(17.6 \%)$. MSCT was done for 37 cases, and 36 patiens $(97.3 \%)$ showed arterial lession. Vasospasm was the most common pathological morphology- 38 pts-53.6\%, treated with Fogarty's dilatation. Arterial contusion was seen in 16 pts-28.5\% (direct anastomosis or autologue veine graft); and thrombose in 2 pts (thrombectomy). All of patients presented warm and pink hand after surgery and radial artery can be palpated easily in $87.5 \%$ of total patients. Conclusion: Supracondylar fracture

\section{I. ĐẶT VẤN ĐỀ}

Gãy trên lồi cầu xương cánh tay là loại gãy rất thường gặp ở trẻ em, chiếm 50-60\% trong số gãy xương vùng khuỷu [1] và $3 \%$ trong số gãy xương nói chung ở trẻ em [2] và là nguyên nhân hay gặp nhất của tổn thương động mạch cánh tay ở trẻ em [3] với tỉ lệ $17.6 \%$ [4].

Mặc dù là bệnh cảnh của chân thương động mạch chi, nhưng đặc điểm chẩn đoán ,hình thái giải phẫu bệnh cũng như phương pháp phẫu thuật cho tổn thương này ở trẻ em gãy trên lồi câu có nhiều khác biệt [5]. Do đó chúng tôi thực hiện nghiên cứu này nhằm mục đích mô tả đặc điểm lâm sàng, cậ̂n lâm sàng khi chẩn đoán, hình thái giải phẫu bệnh,phương pháp phẫu thuật và kết quả sớm sau mổ ở những bệnh nhân tổn thương động mạch cánh tay trong gãy trên lồi cầu xương cánh tay.

\section{II. ĐỐl TƯỢNG VÀ PHƯƠNG PHÁP NGHIÊN CỨU}

Nghiên cứu được tiến hành theo phương pháp mô tả cắt ngang. Đối tượng là tất cả người bệnh nhi dưới 16 tuổi, được chẩn đoán gãy trên lồi cầu xương cánh tay có tổn thương mạch máu và đã được phẫu thuật tại Bệnh viện Hữu nghị Việt Đức. Thời gian nghiển cứu từ 01/01/2015 đển 31/12/2020.

Các biến số nghiên cứu bao gồm các đặc điểm lâm sàng và cận lâm sàng trước mổ ,hình thái giải phẫu bệnh trong mổ và phương pháp phẫu thuật, kết quả sớm sau mổ. Xử lý số liệu bằng phần mềm thống kê SPSS20.0.Quản lý tài liệu tham khảo bằng phần mềm Zotero.

Qui trình nghiên cứu: Sau khi nhập viện, bênh nhi được thực hiện thăm khám lâm sàng và xét nghiệm cận lâm sàng để thực hiện chẩn đoán gãy trên lồi cầu xương cánh tay có tổn thương mạch máu và được chỉ định phẩu thuật. Phẫu thuật được thực hiện để đánh giá tổn thương và phục hồi lưu thổng mạch máu, cùng với xử lý tổn thương gãy xương. Toàn bộ quá trình trên được ghi nhận, lưu thông tin khách quan từ hồ sớ bệnh án và xử lý theo các phần mềm thống kê khoa học.

Đạo đức nghiên cứu: Nghiên cứu được tiến hành có sự đồng ý của gia đình người bệnh,

Trường Đại Học $Y$ Hà Nội và Bệnh Viện Hữu Nghị Việt Đức; thông tin trong hồ sơ bệnh án chỉ được dùng cho mục đích nghiên cứu, đảm bảo trung thực, chính xác và bí mật.

\section{KẾT QUẢ NGHIÊN CỨU}

Trong thời gian từ 01/01/2015 đến 31/21/2020, có tổng số 56 bệnh nhi đủ điều kiện đưa vào nghiên cứu với các đặc điểm như sau.

\section{1. Đặc điểm chung:}

\section{- Giới tính:}

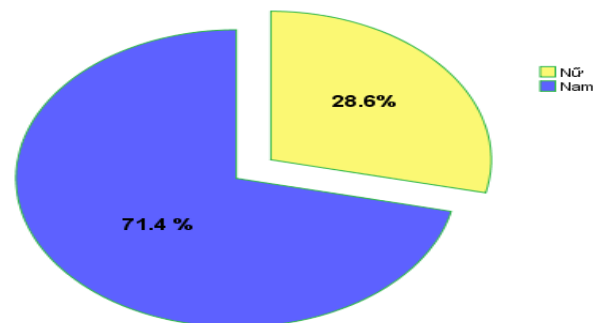

Biểu đồ 1: Phân bố bệnh nhân theo giới tính $(N=56)$

Nhận xét: nam thường gặp hơn nữ (tỉ lệ khoảng 2/1)

- Tuổi:

Bảng 1: Phân bố bệnh nhân theo nhóm tuổi $(N=56)$

\begin{tabular}{|c|c|c|c|c|}
\hline Tuối BN & \multicolumn{2}{|c|}{ Trung bình } & \multicolumn{3}{c|}{ Nhỏ nhất } & \multicolumn{1}{c|}{ Lớn nhất } \\
\hline & $6.3 \pm 2.7$ & \multicolumn{3}{|c|}{1} \\
\hline Nhóm tuối & {$[\mathbf{1 - 3}]$} & {$[\mathbf{4 - 8}]$} & {$[\mathbf{9 - 1 3}]$} & {$[\mathbf{1 4 - 1 6}]$} \\
\hline Tỉ lệ & $10.7 \%$ & $76.8 \%$ & $12.5 \%$ & $0 \%$ \\
\hline
\end{tabular}

Nhân xét: Nhóm từ 4-8 tuối có tỉ lệ cao nhất.

2. Bệnh cảnh lâm sàng 


\section{BÀN LUÂN}

1. Bệnh cảnh lâm sàng. Gãy trên lồi cầu ở trẻ em có tỉ lệ nam và nữ gần như bằng nhau[6]. Trong nghiên cứu này tî lệ bệnh nhân nam chiếm tới $71 \%$ (Biểu đồ 1 ), có thể là do đặc tính hiếu đông, vận động nhiêuu hơn ở các trẻ nam. Độ tuổi hay gặp nhất cũng trong khoảng 56 tuổi (Bảng 1), là độ tuổi trẻ nhỏ chuẩn bị hoăc đã bắt đâuu tới trường học. Gần như chỉ gặp gã̃y kín và do ngã khi chơi đùa (chiếm 98,2\%), chỉ có 1 trường hợp gãy hở do bị gia súc (trâu) đá vào tay. Cũng chính vì tổn thương chủ yếu theo cơ chế ngã chống tay và độ cao không lớn nên khi đến bệnh viện tất cả đều có toàn trạng ổn định, không có trường hợp nào có các biến loạn toàn thân đáng kể hay đa chấn thương.

Đa phần bệnh nhân đến viện có gãy di lệch mức độ nhiều (Gartland III) chiếm $87,5 \%$ và không có trường hợp nào gãy ít di lệch (Gartland I). Điều này phù hợp với cơ chế tổn thương động mạch cánh tay trong gãy trên lồi cầu là động mạch bị kẹt vào ổ gãy. Đa số bệnh nhi khi đến bệnh viện không có triệu chứng thiếu máu rõ ràng, chì một số ít có biểu hiện đầu chi lạnh và không trường hợp nào có biểu hiện thiếu máu chi nặng hoặc không hồi phục, điều vẫn gặp ở chấn thương mạch máu chi ở người lớn, chủ yếu do vòng nối tuần hoàn vùng cánh tay, khuỷu tay xuống nuôi dưỡng cẳng bàn tay tương đối phong phú. Do vậy, thời gian từ khi bị tai nạn tới khi đến bệnh viện cũng như được phẫu thuật (lần lượt tương ứng là 11,5 giờ và 2,2 ngày - Bảng 2 ) cũng dài hơn nhiều so với thời gian vàng ( 6 giờ sau tai nạn) để phục hồi lưu thông sau tắc mạch chi cấp ở người lớn. Ngoài lý do thiếu máu chi không cấp tính, quá trình thực hiên nắn bột (có thể nhiều lần) cũng như khó khằn khi thực hiện các xét nghiệm chẩn đoán hình ảnh, đặc biệt là chụp MSCT hệ mạch cánh tay cũng đòi hỏi nhiều thời gian, do đó kéo dài thời gian trước khi phẫu thuật.

2. Kết quả chẩn đoán hình ảnh trước phẫu thuật. Do bệnh cảnh lâm sàng thiếu máu không điển hình, khó khai thác ở các cháu nhỏ, nhất là các cháu chưa đến độ tuổi đi học nên các biện pháp chẩn đoán hình ảnh mạch máu rất quan trọng để đưa ra quyết định phẫu thuật hay chỉ nắn bôt. Tuy nhiên do các cháu nhỏ đa phần ở độ tuổi chưa đi học, không hoặc ít có sự hợp tác tốt nên các biện pháp chẩn đoán hình ảnh mạch máu đều rất khó được thực hiện trong điểu kiện tốt nhất. Về cơ bản, muốn thực hiện các xét nghiệm chẩn đoán mạch máu (siêu âm doppler, chụp MSCT) đều phải tiến hành gây mê, dẫn tới những khó khăn để triển khai về nhân lực, trang thiết bị cũng như tăng nguy cơ tai biến.

Chính vì thực hiện trong điêu kiện thông thường, cấp cứu, thiếu sự hợp tác tốt nên chỉ một số rất nhỏ dưới 20\% (Bảng 4) siêu âm doppler đánh giá được tình trạng mạch máu ở ngang ổ gãy (bao gồm cả thành mạch và lòng mạch), là vị trí quyết định tới chẩn đoán chấn thương động mạch chi. Sự khó khăn khi thực hiện đánh giá tình trạng mạch máu ngang ổ gã̃y còn do nhiều yếu tố khác như: vướng bởi bột, băng, vết thương (gãy hở), tổ chức xung quanh phù nề, khối máu tụ lớn.

Trong nghiên cứu, hơn một nửa số bệnh nhi được chụp MSCT hệ mạch chi trên (Bảng 4), khác xa so với chẩn đoán chấn thương mạch máu chi ở người trưởng thành, rất hiếm khi phải sử dụng tới biện pháp chẩn đoán này. Lý do chủ yếu là triệu chứng lâm sàng không điển hình, thiếu máu chi không cấp tính cũng như siêu âm doppler không đủ cơ sở để khẳng định chẩn đoán. Tuy nhiên, MSCT cho phép đánh giá toàn thể tình trạng tưới máu của toàn bộ hệ thống mạch máu của tay, bao gồm cả tuần hoàn bàng hệ nhưng cũng không đánh giá được thật chính xác thương tổn thành mạch và lòng mạch ở trẻ em.

3. Thương tổn mạch máu, xử trí phẫu thuật và các yếu tố liên quan. Hơn $2 / 3$ số trường hợp có thương tổn động mạch cánh tay là co thắt tương ứng với vị trí gãy xương mà không có thương tổn thành mạch rõ ràng trong khi chỉ $1 / 3$ còn lại có tổn thương thành mạch thực sự là đụng dập kèm huyết khối lòng mạch hoặc đứt rời (Bảng 5). Phần lớn trường hợp, sau nắn và găm kim, mạch máu đã được giải phóng khỏi ổ gãy, chỉ số ít vẫn mắc vào ố gãy. Các trường hợp co thắt mach sẽ được phục hồi lưu thông bằng phong bể papaverin lớp áo ngoài hoặc mở mạch, nong bằng bóng Forgaty (Hình 1).

Với tổn thương đụng dập, phẫu thuật cắt bỏ đoạn mạch đụng dập, nối trực tiếp được lựa chọn.

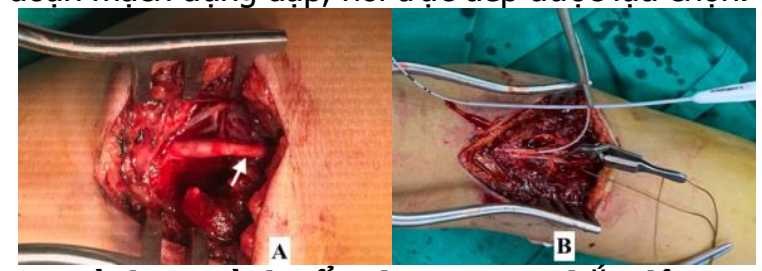

Hinh 1: Hình tồn thương co thăt động mach cánh tay và xử trí phẫu thuật

A: Thành mạch co nhỏ; B: Nong động mạch bằng bóng Forgaty

Trong nghiên cứu, chỉ sử dụng duy nhất kĩ thuật cắt nối mạch trực tiếp khi có thương tổn thực thể thành mạch mà ít khi ghép đoạn bằng tĩnh mạch hiển như ở người lớn vì tất cả đều có 
tổn thương ngắn (dưới $1 \mathrm{~cm}$ ) (Hình 2). Ngoài ra nếu lựa chọn ghép đoạn bằng tĩnh mạch hiển thì cũng rất khó khăn vì kích thước tĩnh mạch này ở trẻ em rất nhỏ, không thể sử dụng được. Tuy nhiên ở trẻ lớn, khi kích thước tĩnh mạch đủ lớn, có thể sử dụng kĩ thuật ghép đoạn động mạch khi tổn thương thành mạch dài, tránh bỏ sót tổn thương dẫn tới tắc mạch sau mổ. Trong nghiên cứu này, có 2 trường hợp sử dụng tĩnh mạch hiển tự thân để ghép đoạn, đều là các trẻ lớn, trên 8 tuổi.
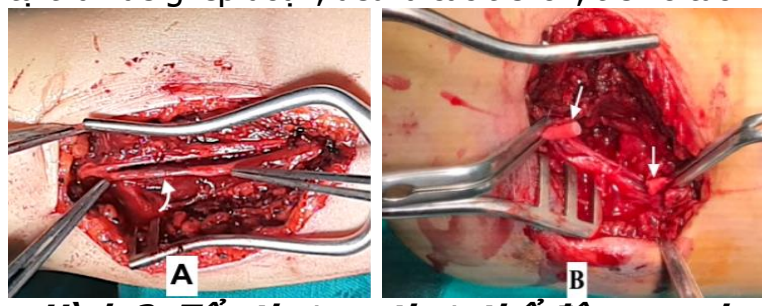

Hình 2: Tôn thương thức thể đông mach cánh tay và xử trí phẫu thuật (stt 31)

A. Đụng dập, huyêt khối, đứt gần rời động mạch cánh tay, B. Cắt đoạn mạch tôn thương, nối trực tiếp

Sau mổ hầu hết các bệnh nhi đều được phục hồi lưu thông mạch máu chi với kết quả tốt: tay hồng ấm, mạch quay bắt rõ, siêu âm kiểm tra có phổ mạch và tốc độ dòng chảy tốt. Tuy nhiên có 2 trường hợp bi tắc mạch phải phẫu thuật lại (Bảng 6). Nguyên nhân gây tắc ngoài việc không cắt bỏ hết tổn thương, còn có thể do kĩ thuật làm miệng nối bị hẹp hoặc sử dụng thuốc chống đông. Cả hai trường hợp này sau đó đều ra viện với kết quả tốt.

\section{KẾT LUÂ̂N}

Đa phần gãy trên lồi cầu có tổn thương động mạch cánh tay không có triệu chứng thiếu máu chi cấp tính giống như chấn thương động mạch ngoại vi ở người lớn, do đó không cần xử trí phục hồi lưu thông mạch máu cấp cứu cho mọi trường hợp. Việc chẩn đoán rất cần phối hợp giữa lâm sàng, siêu âm và cắt lớp vi tính để xác định chính xác tổn thương. 53,6\% trường hợp tổn thương co thắt động mạch liên quan tới ổ gãy xương, nhưng không có thương tổn thực thể thành mạchhoặc trong lòng động mạch cánh tay. Phẫu thuật vẫn là phương pháp quyết định để chẩn đoán tổn thương và phục hồi lưu thông mạch máu.

\section{TÀI LIÊU THAM KHẢO}

1. Phan Quang Trí (2014). Gãy trên hai lồi cầu xương cánh tay ở trẻ em có tổn thương mạch máu và hội chứng Volkmann. Tạp chí Y học thực hành, 903, 82-83.

2. Abzug J.M. and Herman M.J. (2012) Management of supracondylar humerus fractures in children: current concepts. J Am Acad Orthop Surg, 20(2), 69-77.

3. Sharma S., Singh V.P., and Bera S. (2019). Brachial artery injury in pediatric patients: review of management and outcome in 29 patients. Int Surg J, 6(12), 4419.

4. Usman R., Jamil M., and Hashmi J.S. (2017). Management of Arterial Injury in Children with Supracondylar Fracture of the Humerus and a Pulseless Hand. Ann Vasc Dis, 10(4), 402-406.

5. Rehman Z.U., Riaz A., and Nazir Z. (2020). Peripheral Arterial Injuries in Children: An Audit at a University Hospital in Developing Country. Ann Vasc Dis, 13(2), 158-162.

6. David S, Flynn J.M (2014). The pediatric upper extremity, Spinger, New York.

7. Phan Quang Trí (2016). Nghiên cứu điều trị gãy trên lồi cầu xương cánh tay kiểu duỗi ở trẻ em bằng nắn kín và xuyên kim qua da dưới màn tăng sáng., Luận án tiến sĩ, Đại học Y Dược Thành phố Hồ Chí Minh.

\title{
KHẢO SÁT RỐI LOẠN DẠ DÀY RUỘT Ở BỆNH NHÂN THÂ̂N NHÂN TẠO CHU KỲ TẠI BÊ̂NH VIÊ̂N ĐA KHOA KHU VỰC THÜ ĐỨC
}

\author{
Đào Bùi Quý Quyền ${ }^{1}$, Nguyễn Thị Bé2, Lê Việt Thắng ${ }^{2}$
}

\section{TÓM TẮT}

Mục tiêu: Xác định đặc điểm rối loạn dạ dày ruột theo bảng điểm Gastrointestinal Symptom Rating

\footnotetext{
${ }^{1}$ Bệnh viện Chợ rẫy, TP Hồ Chí Minh

${ }^{2}$ Học viện Quân y

Chịu trách nhiệm chính: Lê Việt Thắng

Email: lethangviet@yahoo.com.uk

Ngày nhận bài: 13/4/2021

Ngày phản biện khoa học: 8/5/2021

Ngày duyệt bài: 21/5/2021
}

Scale-GSRSở bệnh nhân bệnh thận mạn giai đoạn cuối thận nhân tạo chu kỳ. Đối tượng và phương pháp: Nghiên cứu cắt ngang trên 80 bệnh nhân thận nhân tạo chu kỳ. Tất cả các bệnh nhân điều được hỏi tình trạng rối loạn dạ dày ruột theo bảng điểm GSRS. Kết quả: Điểm GSRS trung bình là $8(2,25$ - 13), có $80 \%$ bệnh nhân xuất hiện ít nhất 01 triệu chứng dạ dày ruột. Nhóm bệnh nhân tuổi $\geq 60$; lọc máu $\geq 10$ năm có chỉ số GSRS trung bình cao hơn nhóm không có đặc điểm trên, $p<0,01$. Có mối tương quan nghịch điểm GSRS với nồng độ hemoglobin và albumin máu, $\mathrm{p}<0,01$. Kết luận: Rối loạn dạ dày ruột là thường 